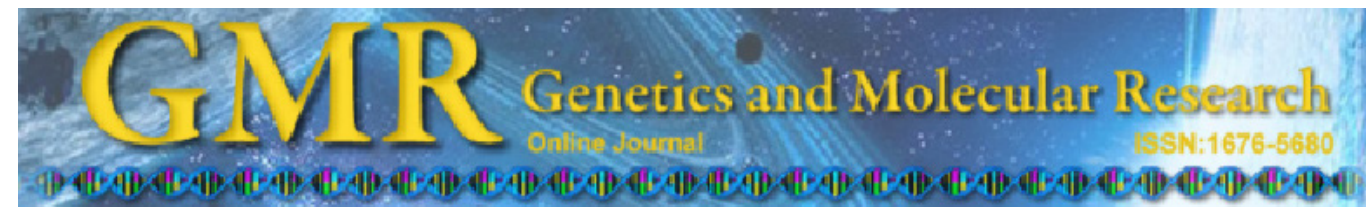

Short Communication

\title{
Assessment of clinical scoring systems for the diagnosis of Williams-Beuren syndrome
}

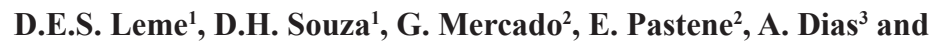 \\ D. Moretti-Ferreira ${ }^{1}$
}

${ }^{1}$ Serviço de Aconselhamento Genético, Departamento de Genética, Instituto de Biociências de Botucatu, Universidade Estadual Paulista, Botucatu, SP, Brasil

${ }^{2}$ Centro Nacional de Genética Médica,

Administración Nacional de Laboratorios e Institutos de Salud,

Buenos Aires, Argentina

${ }^{3}$ Departamento de Saúde Pública, Faculdade de Medicina de Botucatu, Universidade Estadual Paulista, Botucatu, SP, Brasil

Corresponding author: D. Moretti-Ferreira

E-mail: sag@fmb.unesp.br

Genet. Mol. Res. 12 (3): 3407-3411 (2013)

Received December 20, 2012

Accepted April 16, 2013

Published September 4, 2013

DOI http://dx.doi.org/10.4238/2013.September.4.7

ABSTRACT. Williams-Beuren syndrome (WBS) is a genetic disorder
characterized by physical and intellectual developmental delay,
associated with congenital heart disease and facial dysmorphism.
WBS is caused by a microdeletion on chromosome 7 (7q11.23), which
encompasses the elastin $(E L N)$ gene and about 27 other genes. The
gold standard for WBS laboratory diagnosis is FISH (fluorescence in
situ hybridization), which is very costly. As a possible alternative, we
investigated the accuracy of three clinical diagnostic scoring systems in
250 patients with WBS diagnosed by FISH. We concluded that all three
systems could be used for the clinical diagnosis of WBS, but they all
gave a low percentage of false-positive $(6.0-9.2 \%)$ and false-negative 
$(0.8-4.0 \%)$ results. Therefore, their use should be associated with FISH testing.

Key words: Williams-Beuren syndrome; Clinical diagnosis; Fluorescence in situ hybridization; Elastin (ELN) gene; Chromosome 7

\section{INTRODUCTION}

Williams-Beuren syndrome (WBS), first described by Williams et al. (1961) and Beuren (1972), is a genetic disorder that leads to physical and intellectual developmental delay associated with congenital heart diseases and facial dysmorphisms. WBS is caused by a microdeletion on chromosome 7 (7q11.23), which encompasses the elastin gene (ELN) and about 27 other genes. ELN haploinsufficiency is responsible for supravalvular aortic stenosis (SVAS), the most severe WBS clinical characteristic (Merla et al., 2010; Schubert, 2009).

Mothers usually report the pregnancy of a child with WBS as uneventful. An infant with WBS often has difficulty feeding and sleeping and may be brought for medical care because of frequent crying, constipation, and especially hernias (most commonly of the inguinal type). WBS patients start walking late, at around two and half years of age. Facial features include prominent forehead and full cheeks, deep-set eyes, flattened nasal bridge with small upturned nose and long philtrum, wide mouth, and full lower lip. The cognitive profile includes over-friendliness, loquacity, and uninhibited. WBS patients show mild to moderate mental retardation with IQ ranging between 50 and 60, hyperacusia, very good memory, and deep hoarse voice (Williams et al., 1961; Beuren, 1972; Souza et al., 2007).

The estimated incidence of WBS is 1:7500 live births (Stromme et al., 2002). Cases are generally sporadic, or de novo, but autosomal dominant inheritance has been reported. The deletions in the WBS region arise as a consequence of misalignment of gametes during meiosis following unequal crossing over (non-allelic homologous recombination) due to high similarity of low-copy-repeat sequence blocks (Schubert, 2009).

In the population of WBS patients, about $30 \%$ of parents carry a heterozygous inversion of the WBS locus (presence of this inversion predisposes to chromosomal mispairing in meiosis). In the non-WBS population, this inversion is present in about 5\% (Schubert, 2009). In $90 \%$ of the cases, WBS microdeletion is $1.55 \mathrm{Mb}$, whereas $1.88 \mathrm{Mb}$ in $8 \%$ of the cases, and atypical sizes are observed in only $2 \%$ (Pober, 2010).

WBS diagnosis is mostly clinical. Laboratory tests using molecular biology techniques can be used to identify the WBS microdeletion. The gold standard for WBS laboratory diagnosis is the fluorescence in situ hybridization (FISH), which, despite being effective, is very expensive. Another molecular method is the multiplex ligation-dependent probe amplification (MLPA), which allows the detection of deletions in specific target sequences, by amplifying over 40 different types of probes, and simultaneous hybridization (Schouten et al., 2002). MLPA is not as expensive as FISH, but it is still not widely available. There is also microarray-based comparative genomic hybridization, which, in comparison with karyotyping, is able to detect chromosomal alterations (deletions and duplications) not visible under a light microscope. However, it does not permit identifying the structural organization of a chromosomal aberration, and is as costly as FISH (Riegel et al., 2011).

To improve WBS clinical diagnosis and to improve the use of molecular techniques 
that can help establish such diagnosis, Lowery et al. (1995) proposed a scoring system that classifies WBS patients as classic or uncertain. The American Academy of Pediatrics (AAP, 2001) recommends the use of a system that is based on the patient's score and indicates whether FISH should be performed. Sugayama et al. (2007) developed a system in which a total score lower than "standard" points out the need for FISH testing to establish the diagnosis.

Within this context, the scoring systems proposed by Lowery et al. (1995), AAP (2001), and Sugayama et al. (2007) were used in a group of patients from Brazil and Argentina with clinically suspected WBS, who had not undergone any kind of score-based evaluation or laboratory molecular testing. The diagnostic accuracy of the clinical features of the scoring systems was compared with that of the gold standard, FISH test.

\section{MATERIAL AND METHODS}

Cases of suspected WBS registered in the databases of Serviço de Aconselhamento Genético, Instituto de Biociências de Botucatu, Universidade Estadual Paulista, Botucatu, SP, Brazil, and of Centro Nacional de Genética Médica, Administración Nacional de Laboratorios e Institutos de Salud, Buenos Aires, Argentina, were randomly selected and reviewed. All patients were assessed by experienced clinical geneticists who completed clinical charts for each case.

The references of the clinical signs used in the scoring systems were described by the AAP (2001). The suspected patients with 3 or more clinical signs, whose frequency was equal to or greater than $60 \%$, underwent FISH testing.

Thus, the clinical diagnostic scoring systems proposed by Lowery et al. (1995), AAP (2001), and Sugayama et al. (2007) were used in 250 patients with WBS: 149 Brazilian patients [140 FISH (+) and 9 FISH (-)], and 101 patients from Argentina [88 FISH (+) and 13 FISH (-)].

Lowery et al. (1995) reviewed the clinical findings for 110 patients with WBS confirmed by FISH, and developed a scoring system that classified WBS patients according to 6 different phenotypes. Patients scoring 0-3 were classified as "uncertain", and patients scoring 4-10 were classified as "classic". Clinical features were grouped as follows: facial characteristics: 3 points; mental retardation, non-SVAS congenital heart disease, or inguinal hernia: 1 point; and SVAS or hypercalcemia: 2 points.

The AAP (2001) developed a system on the basis of a study of 107 individuals with WBS confirmed by FISH. This system is divided into 7 items: growth (if 3 of 5 items are checked, 1 point is scored), behavior (if 3 of 6 items are checked, 1 point is scored), development (if 3 of 6 items are checked, 1 point is scored), facial features (if 8 of 17 items are checked, 3 points are scored), cardiovascular problems-SVAS (if 1 of 2 items is checked, 1 point is scored), non-SVAS cardiovascular problems (if 1 of 3 items is checked, 5 points are scored), connective tissue abnormality (if 2 of 6 items are checked, 2 points are scored), and calcium studies (if 1 of 2 items is checked, 2 points are scored). If the total score is $<3$, a diagnosis of WBS is unlikely. If the score is $\geq 3$, FISH study should be considered.

The scoring system of Sugayama et al. (2007) is based on a meta-analysis including 577 patients and 42 clinical signs. The cut-off score indicating the need for the FISH test is 20. Clinical findings are scored as follows: low birth weight, difficulty feeding, typical facies, SVAS, mental retardation and over-friendliness: 3 points; strabismus and developmental delay: 2 points; failure to thrive, non-SVAS cardiovascular problems, arterial hypertension, joint contractures, hyperacusia, and ungual hypoplasia: 1 point.

The results obtained were compared by statistical methods for the validation of diag- 
nostic tools using the OpenEpi v.2.3 software (Dean et al., 2009). Significance level was set at $5 \%$ for all scoring systems.

\section{RESULTS}

Patient age ranged from 2 months to 31 years. Of the 250 WBS patients included, 227 were FISH (+) and 23 were FISH (-). Thus, the gold standard indicated that in this case series, WBS prevalence was $90.8 \%$. Table 1 shows patient distribution according to the three scoring systems assessed and FISH testing, as well as estimates of sensitivity, specificity, and positive and negative predictive values (PV+ and PV-). Confidence intervals $(95 \% \mathrm{CI})$ were adjusted by the Wilson scoring method, which is favored when adjustment for a single proportion is made (Vollset, 1993).

\begin{tabular}{|c|c|c|c|c|c|c|c|}
\hline & & \multicolumn{2}{|c|}{ FISH } & \multirow[t]{2}{*}{ Sensitivity $(95 \% \mathrm{CI})$} & \multirow[t]{2}{*}{ Specificity $(95 \% \mathrm{CI})$} & \multirow[t]{2}{*}{$\mathrm{PV}+(95 \% \mathrm{CI})$} & \multirow[t]{2}{*}{ PV- $(95 \% \mathrm{CI})$} \\
\hline & & + & - & & & & \\
\hline \multirow[t]{2}{*}{ Lowery et al. (1995) } & + & 224 & 23 & $98.68 \%$ & $0.00 \%$ & $90.69 \%$ & $0.00 \%$ \\
\hline & - & 3 & 0 & $(96.19-99.55)$ & $(0.0-14.31)$ & $(86.42-93.71)$ & $(0.0-56.15)$ \\
\hline \multirow[t]{2}{*}{ AAP (2001) } & + & 217 & 15 & $95.59 \%$ & $34.78 \%$ & $93.53 \%$ & $44.44 \%$ \\
\hline & - & 10 & 8 & $(92.08-97.59)$ & $(18.81-55.11)$ & $(89.61-96.04)$ & $(24.56-66.28)$ \\
\hline \multirow[t]{2}{*}{ Sugayama et al. (2007) } & + & 225 & 19 & $99.12 \%$ & $17.39 \%$ & $92.21 \%$ & $66.67 \%$ \\
\hline & - & 2 & 4 & $(96.84-99.76)$ & $(6.98-37.14)$ & $(88.16-94.96)$ & $(30.9-90.32)$ \\
\hline
\end{tabular}

$\mathrm{PV}+=$ positive predictive values; $\mathrm{PV}-=$ negative predictive values.

All three scoring systems showed high sensitivity, but little or no specificity. The PV+ were high, whereas the PV- were intermediate.

\section{DISCUSSION AND CONCLUSIONS}

Over $95 \%$ of the FISH (+) patients were also clinically diagnosed with WBS, showing that clinical evaluation was infrequently wrong.

However, specificity estimates lower than 35\% (even reaching zero), indicated that scoring systems based on clinical signs may classify unaffected individuals as affected if individuals displaying WBS signs or symptoms or WBS phenocopies are evaluated.

It is worth noting that the validation of diagnostic tests aims at sensitivity/specificity balance, since highly specific tests tend to have low sensitivity, and since highly sensitive tests tend to have low specificity. Our results pointed to the latter case.

PVs are known to depend not only on the test used but also on the prevalence of the disease investigated, which in this case exceeded 90\%. This results in higher PVs when test sensitivity and specificity are fixed, particularly the PV+ (over $90 \%$ for the three scoring systems).

This study clearly demonstrates that WBS can be clinically diagnosed using any one of the three scoring systems assessed. The system proposed by Lowery et al. (1995) is the easiest to apply from the operational standpoint. However, all of them show a small percentage of falsepositive (6.0-9.2\%) and false-negative results (0.8-4.0\%). Thus, the use of FISH testing in combination with clinical evaluation can help in establishing a more accurate and specific diagnosis. 


\section{REFERENCES}

American Academy of Pediatrics (AAP) (2001). Health care supervision for children with Williams syndrome. Pediatrics 107: 1192-1204.

Beuren AJ (1972). Supravalvular aortic stenosis: a complex syndrome with and without mental retardation. Birth Defects Orig. Art. Ser. 8: 45-56.

Dean AG, Sullivan KM, Soe MM and Mir RA (2009). Openepi. V.2.3. Atlanta, USA.

Lowery MC, Morris CA, Ewart A, Brothman LJ, et al. (1995). Strong correlation of elastin deletions, detected by FISH, with Williams syndrome: evaluation of 235 patients. Am. J. Hum. Genet. 57: 49-53.

Merla G, Brunetti-Pierri N, Micale L and Fusco C (2010). Copy number variants at Williams-Beuren syndrome 7q11.23 region. Hum. Genet. 128: 3-26.

Pober BR (2010). Williams-Beuren syndrome. N. Engl. J. Med. 362: 239-252.

Riegel M (2011). Hibridização Genômica Comparativa em Microarranjos ou Array-CGH. In: Citogenética Humana (Maluf SW and Riegel M, eds.). Artmed, Porto Alegre, 273-277.

Schubert C (2009). The genomic basis of the Williams-Beuren syndrome. Cell Mol. Life Sci. 66: 1178-1197.

Souza DH, Moretti-Ferreira D and Rugolo LMSS (2007). Fluorescent in situ hybridization (FISH) as a diagnostic tool for Williams-Beuren syndrome. Genet. Mol. Biol. 30: 17-20.

Stromme P, Bjornstad PG and Ramstad K (2002). Prevalence estimation of Williams syndrome. J. Child Neurol. 17: 269-271.

Sugayama SMM, Leone C, Chauffaille MLLF, Okay TS, et al. (2007). Williams syndrome. Development of a new scoring system for clinical diagnosis. Clinics 62: 159-166.

Vollset SE (1993). Confidence intervals for a binomial proportion. Stat. Med. 12: 809-824.

Williams JCP, Barratt-Boyes BG and Lowe JB (1961). Supravalvular aortic stenosis. Circulation 24: 1311-1318. 